\title{
Application of ADMS and AERMOD models to study the dispersion of vehicular pollutants in urban areas of India and the United Kingdom
}

\author{
S. Nagendra ${ }^{1}$, M. Khare ${ }^{2}$, S. Gulia ${ }^{2}$, P. Vijay ${ }^{1}$, V. S. Chithra ${ }^{1}$, \\ M. Bell ${ }^{3} \&$ A. Namdeo ${ }^{3}$ \\ ${ }^{I}$ Department of Civil Engineering, Indian Institute of Technology, \\ Madras, India \\ ${ }^{2}$ Department of Civil Engineering, Indian Institute of Technology, \\ Delhi, India \\ ${ }^{3}$ School of Civil Engineering and Geosciences, Newcastle University, UK
}

\begin{abstract}
Urban air pollution poses a significant threat to human health, the environment and the quality of life of people throughout the world. In the United Kingdom 103 areas have been declared as local air quality management areas (LAQMA). While in India, 72 cities have been identified as cities having poor air quality/non-attainment area, i.e., the air quality in these cities are exceeding prescribed National Ambient Air Quality Standards (NAAQS). The transport sector is the principal source of local air pollution in urban areas, because of the increased vehicular population, vehicle kilometres travelled (VKT) and lack of infrastructure development.

Many mathematical models have been widely used as tools in local air quality management in developed countries. Among them, ADMS [1] and AERMOD [2] models have been widely used for urban air quality management in Europe and the US, respectively. However, their applications are limited in developing countries like India due to the lack of readily available input data, time and the cost involved in collecting the required model input data. In this paper the performance evaluation of ADMS and AERMOD in predicting particulate matter (PM) concentrations at road sides in Chennai, India and Newcastle, UK is discussed.
\end{abstract}


The statistical parameters such as Index of Agreement (IA), Fractional Bias (FB), Normalized Mean Square Error (NMSE), Geometric Mean Bias (MG) and Geometric Mean Variance (VG) have been used to evaluate the ADMS and AERMOD model performance. Results indicated that both the models are able to predict the pollutant concentrations with reasonable accuracy. The IA values for ADMS and AERMOD are found to be 0.39 and 0.37 and 0.48 and 0.44 , respectively, for the Chennai and Newcastle study sites.

Keywords: air quality models, vehicular pollution, AERMOD, ADMS-urban, statistical indicator and performance evaluation.

\section{Introduction}

Cities are the largest targets of impacts of air pollution due to different human and material activities. In recent years, many cities have experienced poor air quality problems and associated health effects during adverse meteorological conditions. According to the United Nations (UN) study, about 4.9 billion inhabitants out of 8.1 billion will be living in cities throughout the world by 2030 compared to the current level of 2.9 billion out of 6.1 billion [3]. On a global scale, automobiles per capita increased by over $20 \%$ during the last decade. This means the motor vehicle fleet has been growing faster than the overall population growth rate $(1.8 \%$ per year).

Like many cities in the developed country, Indian cities are also growing at a faster rate. The air pollution from motor vehicles is one of the most serious and rapidly growing problems in urban areas. This problem has further been compounded by the concentration of large number of vehicles and comparatively high motor vehicles to population ratios in these cities. During the last two decades, number of registered motor vehicles in India has increased dramatically from 5.4 million in 1980-1981 to 72.7 million in 2003-2004 [4]. The urban population of India, which constitutes $28 \%$ of the total, is predominantly dependent on road transport. About $80 \%$ of passenger and $60 \%$ of freight movement depend on road transport. Traffic composition of major metro cities of India shows that there is significant shift from the share public transport to private transport [5]. In the recent years, enormous progress has been made to tackle air quality problems in urban areas, however, rapid economic growth rate, lack of public transport system and insufficient infrastructure to meet the requirements of urban demand resulted into the deterioration of air quality near urban roadways. Episodes of poor air quality in cities of both developed and developing countries indicated a need for local air quality management system (LAQMS) to protect humans and material from the adverse effects of air pollution [6]. In the United Kingdom 103 areas have been declared as local air quality management areas (LAQMA) [7]. While in India, 72 cities have been identified as cities having poor air quality i.e., the air quality in these cities are exceeding prescribed National Ambient Air Quality Standards (NAAQS) [8].

Air quality models plays important role in urban air quality management [9]. Modeling provides the ability to assess the current and future air quality in order to enable (informed) policy decisions to be made. It also provides a relatively 
inexpensive means of determining compliance and predicting the degree of emission reduction necessary to attain ambient air quality standards. Thus, air quality models play an important role in providing information for better and more efficient air quality management planning. An effective air quality management system must be able to provide the authorities with information on the current and likely future trends, throughout the area enabling them to make necessary assessments regarding the extent and type of the air pollution control management strategies to be implemented.

There are two approaches used in modelling of air pollutants dispersion, namely statistical and the analytical approach. In statistical technique, historical time series data have been used for modelling, whereas in analytical approach, the physical process and cause effect relationship have been related to the final model outcome (Gaussian model). The Gaussian based air quality models namely AERMOD and ADMS-Urban are highly advanced and complex but user-friendly. Kumar et al. [10] observed that AERMOD has a tendency to under-predict both under stable and unstable conditions when the model was applied for Ohio, USA. Long et al. [11] studied that sensitivity of AERMOD to input parameters and found out that AERMOD is very sensitive to surface roughness than other input parameters like solar radiation, cloud cover and albedo. Over 70 U.K. local authorities [1] have extensively used the ADMS Urban for control of air pollution at designated air quality control regions (AQCRs). Mohan et al. [12] found out that AERMOD has a greater tendency to over-predict when compared to ADMS-Urban. This difference is due to difference in treatment of atmospheric stability. Also, use of sophisticated parameterization does not always yield good results as in this case. Both performed better for monthly averages than 24 hourly averages. The performance and accuracy of the air quality models is mainly depends upon accuracy input parameters. In this study, two state-of art air quality models namely AERMOD and ADMS- Urban have been evaluated to predict PM concentration at Sardar Patel (SP) road in Chennai, India and in the city centre in Newcastle, UK.

\section{Methodology}

\subsection{Site characteristics}

Figure 1(a) shows the details of the study area. The study site was located at the out gate of IIT Madras which is very near to SP road. The monitoring site is surrounded by a number of primer educational and research institutes; hence, this region is subjected to intense human activity and vehicular traffic. The instrument is kept at $1.2 \mathrm{~m}$ height from ground level and about $7 \mathrm{~m}$ away from the centerline of SP Road, The traffic volume on the road is extremely high, i.e. $1,70,000$ vehicles per day. The terrain of the study site is considered as plain and flat terrain (terrain height is 7.6 from mean sea level). At this site, there is no local stationary emission sources exist and the main source of PM emission is from road traffic. 


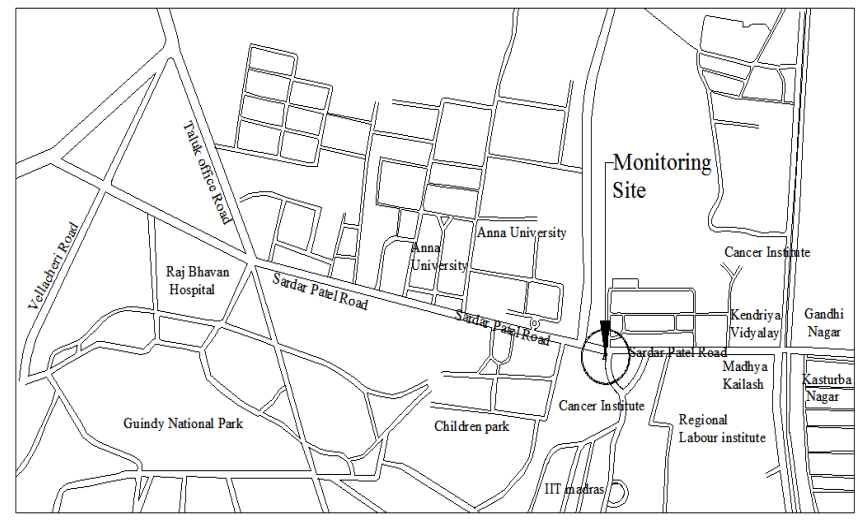

(a)

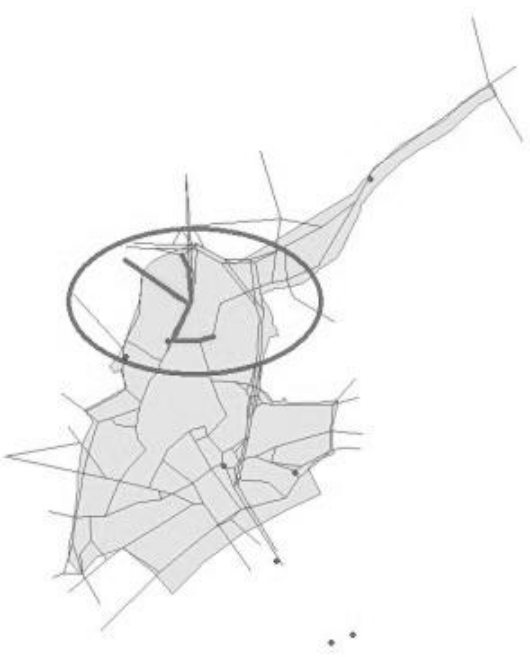

(b)

Figure 1: Description of the study regions (a) Chennai and (b) Newcastle Upon Tyne.

The project site in Newcastle city is located at $54^{\circ} 58^{\prime} 40 \mathrm{~N}$ and $1^{\circ} 36^{\prime} 49^{\prime \prime}$ (Figure 2) which is also one the busiest intersection of Newcastle upon Tyne city. This intersection comes under air quality control regions (AQCRs). The whole intersection has been divided in to three different roads. The monitoring site is situated near to road i.e. $20 \mathrm{~m}$ at city centre. The city centre monitoring station works under urban centre air quality station which is operated under Automatic Urban and Rural Network (AURN), the main air quality compliance network for DEFRA. The monitored data of both cities are used for validation of the model. 


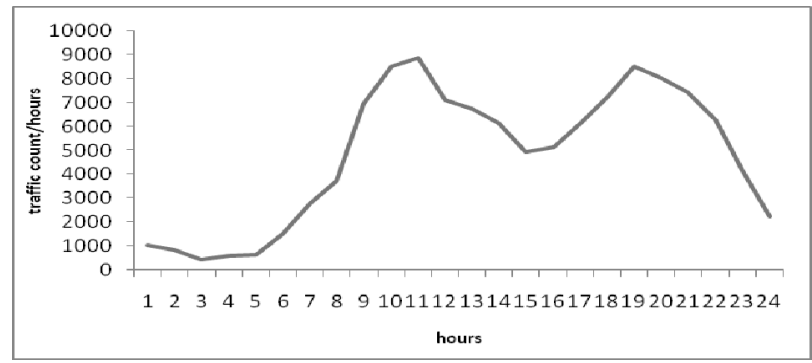

Figure 2: Diurnal pattern of traffic data on SP road, Chennai.

\subsection{Traffic characteristics}

The traffic count has been carried out on SP road for year 2009 for weekdays and weekend by video graphic followed by manual count method. The traffic flow at Chennai intersection is about 1,70,000 and that in the intersection at Newcastle city is about 25000. The morning peak flow occurs between 8 am and 10 am and afternoon peak occurs between $5 \mathrm{pm}$ and $7 \mathrm{pm}$. The diurnal pattern of traffic on SP road has been shown in Figure 2. The traffic fleet of Chennai site consists of $50 \%$ of $2 \mathrm{~W}(2 \mathrm{~S}=22 \%$ and $4 \mathrm{~S}=28 \%)$ and $35 \%$ of cars (petrol driven $=24 \%$ and diesel driven $=11 \%)$. The $3 \mathrm{~W}$ consists of two types - petrol driven $(6 \%)$ and diesel driven $(2 \%)$. The composition of buses is $4 \%$. Figure 3 shows the traffic fleet characteristic of the Chennai site. The vintage profile of the Chennai traffic is given below in Table 1 .

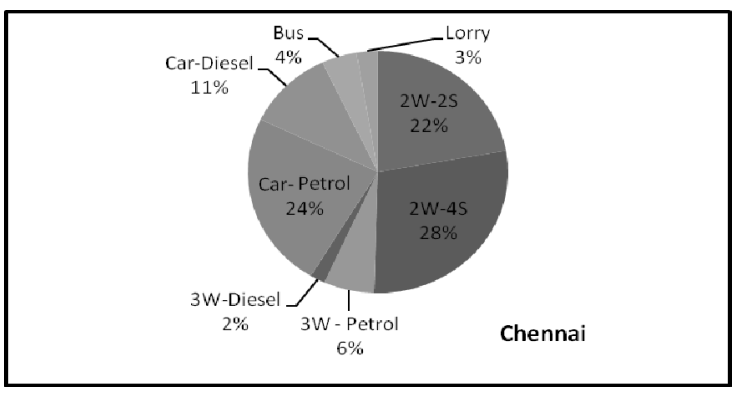

Figure 3: $\quad$ Traffic fleet characteristics of SP road, Chennai.

Table 1: $\quad$ Vintage profile of Chennai traffic.

\begin{tabular}{|c|c|c|c|c|c|}
\hline Year & $\mathbf{2 W}$ & $\mathbf{3 W}$ & cars & Lories & Buses \\
\hline $2006-09$ & 57 & 50 & 50 & 43 & 21 \\
\hline $2000-05$ & 30 & 17 & 30 & 29 & 38 \\
\hline $1996-00$ & 8 & 21 & 14 & 21 & 31 \\
\hline $1990-95$ & 4 & 11 & 6 & 7 & 10 \\
\hline Total & 100 & 100 & 100 & 100 & 100 \\
\hline
\end{tabular}


The traffic flow for Newcastle city has been obtained from SCOOT profile of the central cordon region of Newcastle city. The traffic count data for the Great North Road and St. Marry Place Road is shown in Figure 4. The traffic fleet of the Newcastle site consists of $73 \%$ cars (petrol driven $=60 \%$ and diesel driven $=$ $13 \%$ ) followed by buses i.e. $16.3 \%$. The portion of $2 \mathrm{~W}$ is much less i.e. $0.62 \%$ and the light gasoline vehicles are $9.46 \%$ (Figure 5).

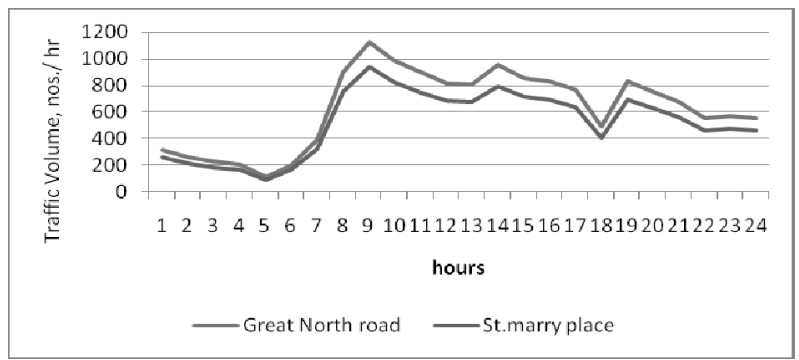

Figure 4: Diurnal traffic pattern city centre intersection, Newcastle site.

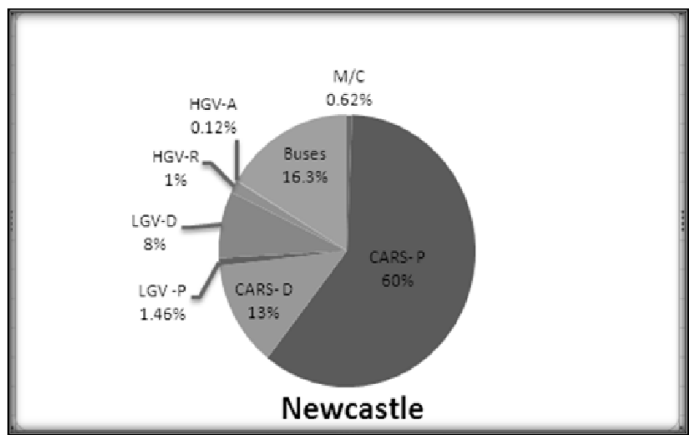

Figure 5: Traffic fleet characteristics of Newcastle site.

The Newcastle traffic fleet comprises more cars/jeeps when compared to Chennai city in India, which predominantly consists of two wheelers (2-stroke and 4-strokes engines). Further, the Newcastle city traffic fleet has $16.3 \%$ of buses; while Chennai traffic fleet comprise only $4 \%$ buses.

\subsection{PM emissions rate}

The emission factors were obtained from the report published by the Automotive Research Association of India, (ARAI), 2007 for Chennai City [13]. The report presents the comprehensive study done on emission factors for India vehicles. These emission factors are developed on chassis dynamometer based on standard driving cycle. The classification of fleet was done based on the vintage and corresponding fuel standards. Emission rate is an important input parameter of any air quality model, which is function of emission factor and vehicular 
activity. The ARAI (2007) emission factors have been used for the Chennai site. The Department of Transport, UK released emission factors for different types of vehicles plying of UK roads [14]. These emission factors have been used for the Newcastle study site which is speed dependent unlike Indian vehicle emission factors.

\subsection{Meteorological data}

The main input meteorological parameters for the AERMOD and ADMS models are wind speed and wind direction plus one of the following parameters, cloud cover, heat flux or reciprocal of Monin-Obukhnov length, upper air data. Sequential hourly meteorological data for the winter period (December 2008February 2009) were obtained from Laga Systems, Hyderabad. The windrose diagram of study period (winter critical) for Chennai and Newcastle has been shown in Figure 6(a) and (b), respectively.

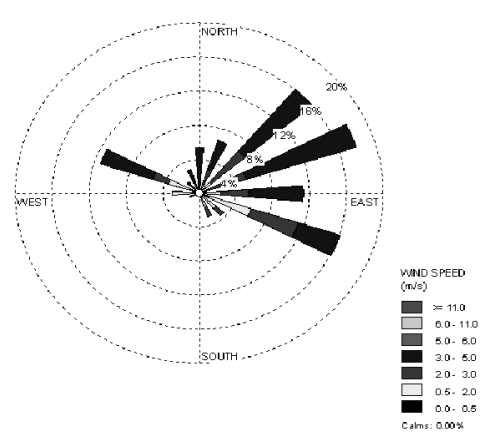

(a) Chennai

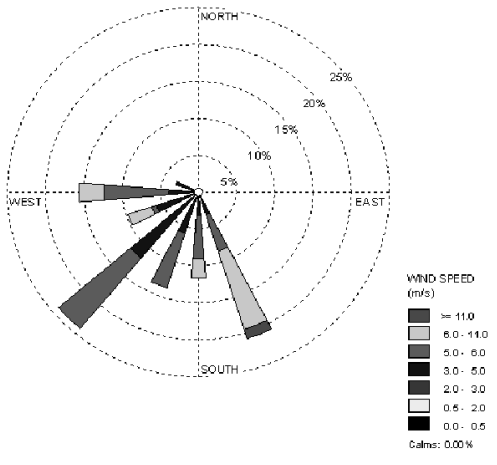

(b) Newcastle

Figure 6: Windrose diagram for winter period of 2009 for (a) Chennai and (b) Newcastle city.

The windrose diagrams revealed that the predominant wind direction is fluctuating between NE and SE at Chennai city and at Newcastle the predominant wind direction is SW and SSE. It is clear from the Windrose diagram that wind speed is high in Newcastle than in Chennai.

\subsection{Description of ADMS urban model}

ADMS - Urban (Atmospheric Dispersion Modelling System) has been developed by Cambridge Environment Research Consultants, United Kingdom. It is an advanced model for calculating concentrations of pollutants emitted both continuously from point, line, volume and area sources, and discretely from point sources. In ADMS-Urban road model sources are treated as line sources. Each road source is decomposed into a maximum of 10 source elements and the concentration of each element is approximated by a crosswind line source of finite length [1]. The model includes algorithms which take account of the 
following: effects of main site building, complex terrain, wet deposition, gravitational settling and dry deposition, short term fluctuations in concentration, chemical reactions, radioactive decay and dose plume rise as a function of distance, jets and directional releases, averaging time ranging from very short to annual; condensed plume visibility meteorological pre-processor.

\subsection{Description of AERMOD model}

AERMOD is a steady-state plume model developed by American Meteorological Society (AMS) and the U.S. Environmental Protection Agency (EPA). The model is applicable to rural and urban areas, flat and complex terrain, surface and elevated releases, and multiple sources (including, point, area and volume sources). This state-of-art model also adopts a Gaussian approach to dispersion modelling. The input requirements of this model are slightly more when compared to other models like ADMS and ISCST3. The basic input requirements can be broadly classified into meteorological data, emission data, geometrical data and pollutant background data.

AERMOD tackles the meteorological data and the terrain data by separate pre-processors called AERMET and AERMAP respectively. AERMET processes the raw meteorological data and generates the parameters required by AERMOD interface to carry out the calculation for the output concentration. AERMAP deals with the elevations of the terrain and produces the receptor grids and elevation contours.

AERMOD is very sensitive to the meteorological and the surface characteristics of the model domain. It presents various options of modelling like regulatory and non-regulatory runs and screening runs etc. it incorporates effects ranging from global radiation to local heat loss. It provides the options to define pollutants in its chemical database.

\section{Results and discussions}

AERMOD and ADMS models are run with the set of meteorological and traffic data. The statistical descriptors Index of Agreement (IA), Fractional Bias (FB), Normalized Root Mean Square Error (NRMSE), Geometric Mean Bias (MG) and Geometric Mean Variance (VG) are used to evaluate the performance of ADMS and AERMOD models. The IA value indicates how much the predicted value departs from observed values. It has a theoretical value between 0 and 1 , latter indicates perfect agreement. NRMSE is an estimator of the overall deviations between the observed and predicted values. Smaller values of NRMSE indicate better performance and are not biased towards model that over predicts or under predict. FB, a dimensionless number, represents the relative difference between observed and modelled values in a bounded range. The value of FB lies between -2 and +2 . MG and $\mathrm{VG}$ are measures of dispersion which finds application when values in a set follow a log normal distribution. A perfect model will have both $\mathrm{MG}$ and $\mathrm{VG}$ equal to 1.0 [8]. However, a model will be deemed acceptable if: NRMSE $\leq 0.5 ;-0.5 \leq \mathrm{FB} \leq 0.5 ; 0.75 \leq \mathrm{MG} \leq 1.25 ; 1 \leq \mathrm{VG} \leq 1.25$ 
[9]. Table 2 presents the summary of AERMOD and ADMS models performance at the Chennai and Newcastle study sites.

Table 2: $\quad$ Statistics of ADMS and AERMOD model performances.

Newcastle

\begin{tabular}{llllllll}
\hline $\mathbf{P M}_{\mathbf{1 0}}$ & IA & FB & MG & VG & NRMSE & $\begin{array}{l}\text { Average } \\
\left(\boldsymbol{\mu g} / \mathbf{m}^{\mathbf{3}}\right)\end{array}$ & $\begin{array}{l}\text { Maximum } \\
\left(\boldsymbol{\mu g} / \mathbf{m}^{\mathbf{3}}\right)\end{array}$ \\
\hline ADMS & 0.48 & -1.19 & 1.07 & 1.14 & 0.09 & 4.44 & 28.10 \\
AERMOD & 0.44 & -1.27 & 1.14 & 0.98 & 0.11 & 3.72 & 24.74 \\
Observed & 1.00 & 0.00 & 1.00 & 1.00 & 0.00 & 16.38 & 59.00 \\
\hline
\end{tabular}

Chennai

\begin{tabular}{llllllll}
\hline PM $_{\mathbf{1 0}}$ & IA & FB & MG & VG & NRMSE & $\begin{array}{l}\text { Average } \\
\left(\boldsymbol{\mu g} / \mathbf{m}^{3}\right)\end{array}$ & $\begin{array}{l}\text { Maximum } \\
\left(\boldsymbol{\mu g} / \mathbf{m}^{\mathbf{3}}\right)\end{array}$ \\
\hline ADMS & 0.39 & -1.03 & 1.12 & 1.04 & 0.17 & 41.33 & 120.11 \\
AERMOD & 0.37 & -1.15 & 1.19 & 1.01 & 0.20 & 20.68 & 86.34 \\
Observed & 1.00 & 0.00 & 1.00 & 1.00 & 0.00 & 130.39 & 343.16 \\
\hline
\end{tabular}

Results indicated that the ADMS model performed better for both the cities when compared to AERMOD. This is indicated by the IA value which measures the uncertainty in predicting the PM values. MG value less than 1 indicates the concentrations values are under predicted. For Newcastle city, the concentrations are under predicted by about $7 \%$ by ADMS and $14 \%$ by AERMOD models. For Chennai, the concentrations are under predicted by about $12 \%$ by ADMS and $19 \%$ by AERMOD models. NMRSE value is lower for ADMS and AERMOD for PM predictions at Newcastle site. This means, models give the results whose overall deviation from the observed values is less. FB values for both the models are negative, hence it indicates that the model under predicting PM concentrations.

\section{Conclusion}

The performance of two Gaussian based air quality models namely ADMS and AERMOD models have evaluated for Indian (Chennai city) and UK (Newcastle city) conditions. Results indicated that ADMS model performed better for both the cities when compared to AERMOD in predicting PM concentrations. The IA for ADMS is found to be 0.39 for Chennai city and 0.48 for Newcastle city.

\section{Acknowledgements}

The research work is a part of the ongoing UKIERI funded research project titled "Evaluation of Quantitative Dispersion Models for Urban Air Quality Assessment. We wish to thank the UKIERI, New Delhi. The authors would like to thanks HSBC (INDIA) for sponsoring the HSBC-UKIERI Senior Research Fellow position to work on this research project. We also acknowledge with 
thanks the CERC, UK who has provided us the ADMS - urban for academic and research purposes on a very competitive price.

\section{References}

[1] CERC, (2006), Cambridge Environmental Research Consultants, ADMS Urban user guide, http://www.cerc.co.uk/environmental-software/ADMSUrban-model.html.

[2] EPA, (2009), AERMOD implementation guide U.S. Environmental Protection Agency, Research Triangle Park, NC.

[3] TEDDY, (2006), Teri Energy Data Directory and Yearbook, 2005-06. Tata Energy Research Institute, New Delhi.

[4] MoF, 2000. Economic Survey 1999-2000. Ministry of Finance, Government of India, New Delhi.

[5] Jalihal, S.A., Ravinder, K., Reddy, T.S., 2005. Traffic characteristics in India. In: Proceedings of the Eastern Asia Society for Transportation Studies, vol. 5, pp. 1009-1024.

[6] Longhurst, J.W.S., Irwin, J.G., Chatterton, T.J., Hayes, E.T., Leksmono, N.S. and Symons J.K., (2009). The development of effects-based air quality management regimes. Atmospheric Environment 43, 64-78.

[7] DEFRA. Department of Environment, Food and Rural Affairs, 2010. http://www.defra.gov.uk

[8] CPCB, (2010), Status of vehicular pollution control program in India, Program Objective Series/PROBES/136/2010. CPCB, 2007. Transport Fuel Quality for the Year 2005. Central Pollution Control Board, Government of India, New Delhi.

[9] Nagendra, S.M.S. and Khare, M., Line source emission modelling- review. Atmospheric Environment, 36 (13), pp. 2083-2098, 2002.

[10] Kumar, A., Dixit, S., Varadarajan, C., Vijayan, A. and Masuraha, A. (2006).Evaluation of the AERMOD Dispersion Model as a Function of Atmospheric Stability for an Urban Area. Environmental Progress (Vol.25, No.2).

[11] Long G.E., Cordova, J. F. and Tanrikulu S. (2004). An analysis of AERMOD sensitivity to input parameters in the San Francisco Bay Area. 13th Conference on the Applications of Air Pollution Meteorology with the Air and Waste Management Assoc. American Meteorological Society, Vancouver, BC, August, 23-25.

[12] Mohan, M., Bhati, S. and Marrapu, P., Performance evaluation of AERMOD and ADMS -Urban models in a tropical urban environment. Indian Journal of Air Pollution Control, 9(1), pp 47-62, 2009.

[13] ARAI, (2007). Emission Factor Development for Indian Vehicles. Project Report No.AEF/2006-07/IOCL/Emission Factor Project. Automotive Research Association of India, Pune (Available on www.cpcb.nic.in)

[14] DfT, (2010), Department for Transport, 2010. http://www.dft.gov.uk 